\title{
Chromosomal characterization of Pseudonannolene strinatii (Spirostreptida, Pseudonannolenidae)
}

\author{
Kleber Agari Campos \& Carmem S. Fontanetti
}

Departamento de Biologia, Instituto de Biociências, Universidade Estadual Paulista (UNESP), Av. 24 A, 1515, 13506-900, Rio Claro, SP, Brazil. (kleber.agari@bol.com.br; fontanet@rc.unesp.br)

\begin{abstract}
The chromosomes of the cave millipede Pseudonannolene strinatii Mauriès, 1974 were investigated. The diploid chromosome number was found to be $2 n=16, \mathrm{XX} / \mathrm{XY}$; the $\mathrm{C}$-banding technique revealed a large amount of heterochromatin while the silver staining technique (Ag-NOR) evidenced the presence of heteromorphism of the NORs in some cells.
\end{abstract}

KEYWORDS. Diplopoda, cytogenetics, caves, heterochromatin.

\section{INTRODUCTION}

Pseudonannolene Silvestri, 1895 is the only representative of the family Pseudonannolenidae in Brazil. For 35 species of Pseudonannolene, eight are found in caves across the different speleological provinces of the country and most of these species are considered troglophiles (TRAJANo et al., 2000).

Pseudonannolene strinatii Mauriès, 1974 lives in many caves of the Speleological Province of the Ribeira River Valley in southern State São Paulo and northern State Paraná (Mauriès, 1974; Trajano et al., 2000).

FonTANETTI et al. (2002) recorded seven species of Pseudonannolene cytogenetically studied and although cytogenetic studies in diplopods have increased considerably during recent years, only about 80 species of millipedes have been studied so far, which is still a small number when compared to the 10,500 species described for this group.

The aim is to describe the karyotype of $P$. strinatti in order to contribute for cytogenetics comprehension in millipedes.

\section{MATERIAL AND METHODS}

Twenty specimens of $P$. strinatii were collected in the Areias de Cima Cave (registered in Brazilian Speleological Society as SP-018) $24^{\circ} 35^{\prime} \mathrm{S}-48^{\circ} 42^{\prime} \mathrm{W}$, Iporanga, State of São Paulo, in Jan/2001, Apr/2001 and Oct/2001, K. A. Campos col. The specimens are deposited in the collection of Departamento de Biologia, Instituto de Biociências, UNESP, Rio Claro, SP, Brazil.

For chromosomal analysis, individuals were starved for one week and then injected with $0.1 \mathrm{ml}$ of $0.08 \%$ colchicine. After approximately 16 hours (overnight), the specimens were dissected in order to extract the midguts, which were placed in tap water for 10 minutes and immediately transferred to Carnoy I fixative. Samples were prepared by the method of cellular suspension, which consists in the centrifugation of the midgut previously dissociated in $45 \%$ acetic acid, followed by two changes of fixative solution and then mounted in slides. Some samples were stained with $3 \%$ Giemsa solution. Staining of the nucleolar organizer regions (NORs) by the silver ion was performed according to HOWELL \& BLACK (1980) and C-banding pattern according to SuMner (1972). Chromosomal characterization in relation to morphology was based on the length of the chromosomal arms and classified according to GUERRA (1986).

\section{RESULTS}

The diploid chromosome number was $2 n=16$, with the sex determination system being XY for males and XX for females (fig. 1). Through the calculation of the chromosomes centromeric index and the ratio of the arms, we obtained values which determined that the complement is composed by two pairs of metacentric chromosomes (pairs 1 and 2), three pairs of submetacentric chromosomes (pairs 3,5 and 7) and two pairs of acrocentric chromosomes (pairs 4 and 6) with the $\mathrm{X}$ chromosome being submetacentric and $\mathrm{Y}$ acrocentric (fig. 1 ; tab. I).

The C-banding shows that pairs 1,2,3, and 5 are almost entirely heterochromatic. In pair 4 and the

Table I. Mean of length arms ratio (R), centromeric index (CI) and morphology (Mo) relating to each chromosomal pair of Pseudonannolene strinatii (m, metacentric; sm, submetacentric; a, acrocentric).

\begin{tabular}{cllc}
\hline Chromosomal pair & \multicolumn{1}{c}{$\mathrm{R}$} & \multicolumn{1}{c}{ CI } & Mo \\
\hline 1 & 1.06 & 48.60 & $\mathrm{~m}$ \\
2 & 1.10 & 47.50 & $\mathrm{~m}$ \\
3 & 2.46 & 28.90 & $\mathrm{sm}$ \\
4 & 3 & 25 & $\mathrm{a}$ \\
5 & 1.97 & 33.70 & $\mathrm{sm}$ \\
6 & 3.68 & 21.35 & $\mathrm{a}$ \\
7 & 1.71 & 36.80 & $\mathrm{sm}$ \\
$\mathrm{X}$ & 2.57 & 28.01 & $\mathrm{sm}$ \\
$\mathrm{Y}$ & 3.04 & 24.75 & $\mathrm{a}$ \\
\hline
\end{tabular}




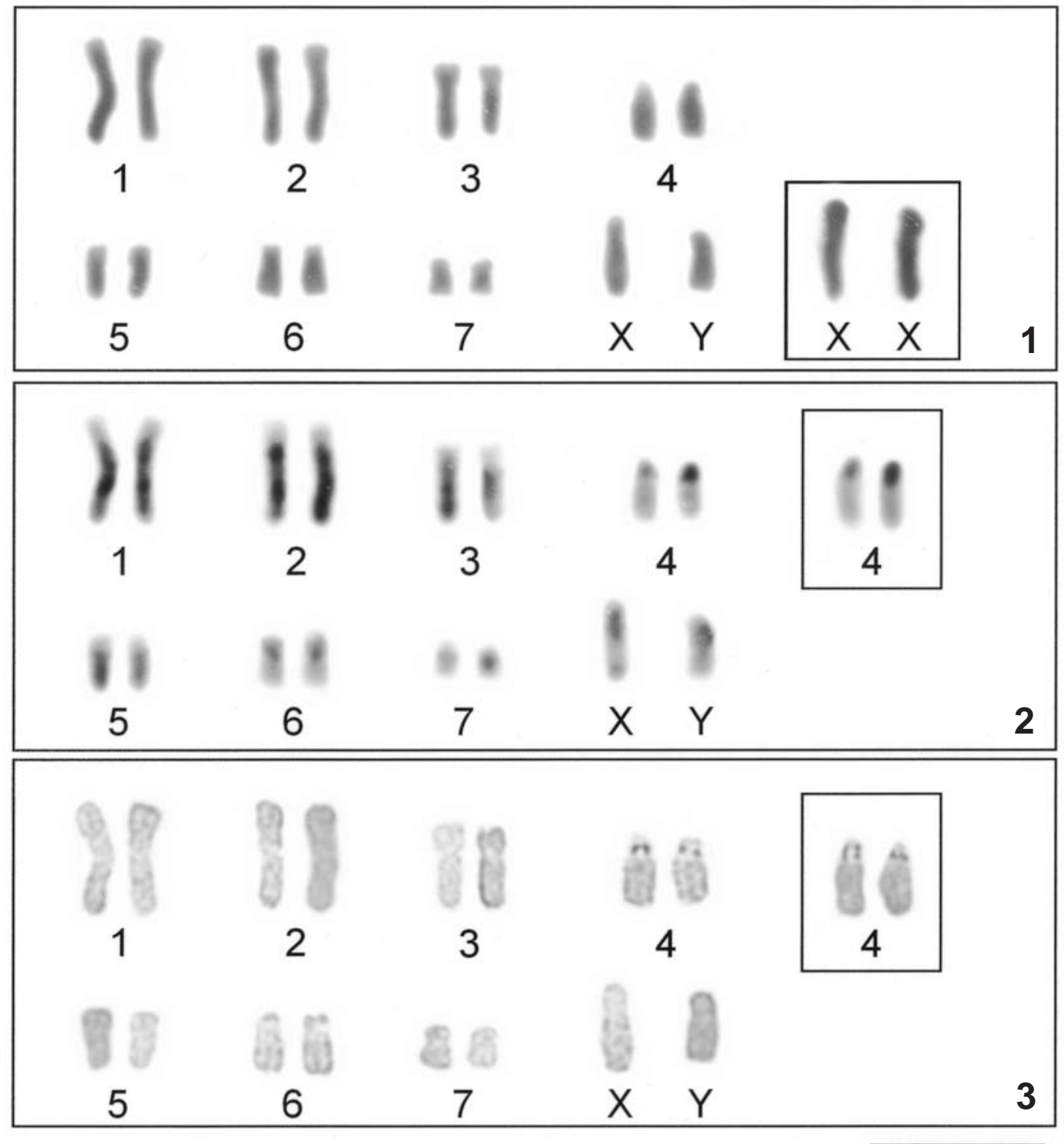

$10 \mu \mathrm{m}$

Figs. 1-3. Karyotype of Pseudonannolene strinatii. 1, Conventional staining with Giemsa, inset indicates the sex chromosomes of females; 2, C-banding technique, inset indicates the C-band of the pair 4 that sourroundings the NOR; 3, Silver staining technique, inset shows the NOR heteromorphism in the pair 4 of some cells.

chromosome $\mathrm{X}$, the short arms are completely heterochromatic with telomeric staining on the long arm of chromosome X. The chromosome Y shows a large heterochromatic band. Pericentromeric heterochromatin is observed in pairs 6 and 7 (fig. 2). The C-banding technique reveals a large amount of constitutive heterochromatin comprising about $65 \%$ of the diploid genome of this species.

The NORs are evidenced at the subterminal position of pair 4 (fig. 3), being this region $\mathrm{C}+$ (fig. 2). In some cells the NORs appear duplicated in one of the elements of the pair (fig. 3, inset).

\section{DISCUSSION}

For the seven species of Pseudonannolene studied cytogenetically, four show a chromosome number of
$2 \mathrm{n}=16$ (FONTANETTI et al., 2002). It is possible to speculate that the basic diploid number for this genus is in fact $2 n=16$.

As observed in $P$. strinatii, VITTURI et al. (1997) described large amount of heterochromatin in the chromosomes of two non-related species of diplopods. In Acanthopetalum sicanum (Berlese, 1883) (Callipodida), heterochromatin comprises $60 \%$ and $56 \%$ of the genome in females and males, respectively, while in Enologus oxypygum (Julida), $67 \%$ of the total genome of either males or females is represented by heterochromatin. Taking into account that an accumulation of heterochromatin of up to 40 or $50 \%$ of the genome has been considered exceptional for other groups of animals, such as insects and amphibians (PETITPIERRE et al., 1988; ScHMID et al., 1995), the percentage observed in diplopods is considerable. 
VitTURI et al. (1997) noticed that the heterochromatin was accumulated in a different manner in the two species studied. Acanthopetalum sicanum showed a typically symmetrical distribution of heterochromatin in relation to the centromere, except in pair 3 and chromosome $\mathrm{Y}$ and E. oxypygum presented an asymmetrical distribution of heterochromatin in all its chromosomes. Stebins (1950) suggests that the difference in the mode of heterochromatin accumulation, independently of function, may be considered as the expression of a karyo-evolutionary line with a tendency to increase the symmetry of a karyotype. In P. strinatii, in which most of the chromosomes show asymmetrically distributed heterochromatin, except for pairs 6 and 7 that show a tendency to symmetrical accumulation in relation to the centromere, we could suggest that the species would be at the middle of this karyo-evolutionary line.

The nucleolar organizer regions, evidenced in pair 4, appeared strongly stained by the C-banding technique. In E. oxypygum, it was noted that $17 \%$ of the total DNA content consists of ribosomal cistrons, which were detected through the FISH technique using rDNA probes (VITTURI et al., 2001). Considering that heterochromatin comprises about $67 \%$ of the genome of this species (VITTURi et $a l ., 1997$ ) and that the FISH staining corresponds to part of the heterochromatic regions, these authors concluded that the $\mathrm{C}+$ material of this species includes ribosomal copies interspersed with highly repetitive constitutive heterochromatin. It was also demonstrated that a small amount of the FISH-positive regions are silver-positive as well, suggesting that the rDNA is only partially active in transcription.

The association between constitutive heterochromatin and nucleolar organizer regions as observed in $P$. strinatii, has been described by several authors in diverse animal groups. In Orthoptera, it has been suggested that the constitutive heterochromatin plays a role in the protection of NORs, since the NOR is of main importance in protein synthesis throughout the cell cycle (SENTIS et al., 1986; WARCHALOWSKA-SLIWA \& MARYANSKA-NADACHOWSKA, 1992; W.-SliwA \& BulgROV, 1997; Rocha et al., 1997). In anuran amphibians, it has been proposed that these $\mathrm{C}+$ blocks next to the NORs restrict genetic recombination to their flanking regions, impeding the formation of chiasmas or forcing their formation in other regions (SCHMID, 1982). This last supposition was confirmed in grasshoppers by JOHN \& KING (1980; 1983) and John et al. (1985). Another hypothesis suggests that particular segments of heterochromatin possess genes that regulate the expression of NORs, suppressor genes would be inactivated by the occurrence of excess heterochromatin in their surroundings (CABRERo et al., 1986).

The silver staining technique revealed heteromorphism in the sizes of NORs in some cells of the individuals studied. Considering that NORs of different sizes are randomly segregated in each population and knowing the existing diversity in their sizes, MACGREGOR et al. (1977) suggested there is much higher probability of finding heterozygous than homozygous chromosomes in salamanders. This variation in the size of Ag-NOR was also observed by SiLva et al. (1999) in the chromosomes of an amphibian. According to the authors, this difference might be attributed to two factors: differential genetic activity of the rDNA segments and duplication of the amount of rDNA. KING et al. (1990) state that the high index of heteromorphisms of the NORs suggests that a significant incidence of non-reciprocal exchange might be occurring among homologues. Unfortunately the lack of deepened studies in cytogenetics of millipedes give us few data to make comparison inside the group, so maybe in the NOR heteromorphism of $P$. strinatii all of these events could be involved.

Acknowledgments. To Dr. P. Gnaspini, Dr. E. Trajano, R. Andrade, R. B. Pascoaloto, F. P. Franco and C. F. Lerche (USP) for providing animals and information during the study; to CNPq for financial support and Instituto Brasileiro do Meio Ambiente e dos Recursos Naturais Renováveis (IBAMA) for collection permission.

\section{REFERENCES}

Cabrero, J.; Navas-Castillo, J. \& Camacho, J. P. M. 1986. Effects of supernumerary chromosome segments on the activity of nucleolar organizer regions in the grasshopper Chorthippus binotatus. Chromosoma, Berlin, 93(4):375-380.

Fontanetti, C. S.; Campos, K. A. et al. 2002. Cytogenetic studies in Diplopoda. Cytologia, Tokyo, 67:253-260.

Guerra, M. S. 1986. Reviewing the chromosome nomenclature of Levan et al. Revista Brasileira de Genética, Ribeirão Preto, 9(4):741-743.

Howell, W. M. \& Black, D. A. 1980. Controlled silver staining of nucleolus organizer regions with protective colloidal developer: a 1-step method. Experientia, Basel, 36(8):1014, 1015 .

John, B. \& KING, M. 1980. Heterochromatin variation in Cryptobothrus chrysophorus. 3. Syntetic hybrids. Chromosoma, Berlin, 78(2):165-186.

1983. Population cytogenetics of Atractomorpha similis. 1. C-band variation. Chromosoma, Berlin, 88(1):57-68.

John, B. \& KING, M. et al. 1985. Equilocality of heterochromatin distribution and heterochromatin heterogeneity in acridid grasshoppers. Chromosoma, Berlin, 91(3-4):185-200.

King, M.; Contreras, N. \& Honeycutt, R. L. 1990. Variation within and between nucleolar organizer regions in Australian hylid frogs (Anura) shown by $18 \mathrm{~S}+28 \mathrm{~S}$ in situ hibridization. Genetica, Dordrecht, 80(1):17-29.

MacGregor, H. C.; Vlad, M. \& Barnett, L. 1977. An investigation of some problems concerning nucleolus organizers in salamanders. Chromosoma, Berlin, 59(4):283-299.

Mauriès, J. P. 1974. Un cambalide cavernicole du Brésil, Pseudonannolene strinatii n. sp. (Myriapoda, Diplopoda). Revue Suisse de Zoologie, Genève, 81(2):545-550.

Petitpierre, E.; Gatewood, J. \& Schimd, C. W. 1988. Satellite DNA from the mealworm beetle Tenebrio molitor. Experientia, Basel, 44(6):498-499.

Rocha, M. F.; Souza, M. J. \& TAshiro, T. 1997. Karyotype variability in the genus Radacridium (Orthoptera, Ramaleidae, Ramaleinae). Cytologia, Tokyo, 62:53-60.

Schmid, M. 1982. Chromosome banding in Amphibia. VII. Analysis of the structure and variability of NORs in Anura. Chromosoma, Berlin, 87:327-344.

Schmid, M.; Feichtiger, W. et al. 1995. Chromosome banding in Amphibia. XXI. Inversion polymorphism and multiple nucleolus organizer regions in Agalychnis callidryas (Anura, Hylidae). Cytogenetics and Cell Genetics, Basel, 69(1-2):18-26.

Sentis, C.; Santos, J. \& Fernandez-Piqueras, J. 1986. Cheterocromatin polymorphism in Baetica ustulata: Intraindividual variation and fluorescence banding patterns. Chromosoma, Berlin, 94(1):65-70.

Silva, A. P. Z.; Haddad, C. B. \& Kasahara, S. 1999. Nucleolus organizer regions in Physalaemus cuvieri (Anura, Leptodactylidae), with evidence of an unique case of Ag-NOR variability. Hereditas, Lund, 131(2):135-141. 
Stebins, G. L. 1950. Variation and evolution in plants. New York, Columbia University. 420p.

Sumner, A. T. 1972. A simple technique for demonstrating centromeric heterochromatin. Research, San Diego, 75(1):304-306.

Trajano, E.; Golovatch, S. I. et al. 2000. Synopsis of Brazilian cave-dwelling millipedes (Diplopoda). Papéis Avulsos de Zoologia, São Paulo, 41(5):213-241.

VitTuri, R.; Colomba, M. S. et al. 1997. High heterocromatin content in somatic chromosomes of two unrelated species of Diplopoda (Myriapoda). Chromosome Research, Oxford, 5(6):407-412.
- 2001. 18S-28S rDNA is interspersed throughout heterochromatin in the millipede Enologus oxypygum (Diplopoda). Genetica, Dordrecht, 110(2):151-155.

Warchalowska-Sliwa, E. \& Bulgrov, A. G. 1997. Cheterochromatin variation in Deracantha onos (Pall) (Deracanthini: Bradyporinae: Tettigoniidae: Orthoptera). Cytologia, Tokyo, 62:7-12.

Warchalowska-Sliwa, E. \& Maryanska-Nadachowska, A. 1992. Karyotype, C-bands and NORs locations in spermatogenesis of Isophya brevipennis Brunner (Orthoptera: Phaneropteridae). Caryologia, Firenze, 45(1):83-89. 